\title{
Role of Sympathetic Activity in the Generation of Heart Rate and Arterial Pressure Variability in Fetal Sheep ${ }^{1}$
}

\author{
JEFFREY L. SEGAR, DAVID C. MERRILL, BRUCE A. SMITH, AND JEAN E. ROBILLARD \\ Departments of Pediatrics /J.L.S., B.A.S., J.E.R./ and Obstetrics and (ilne'ology /D.C..1/./. Lniversit! of Iowa \\ College of Medicine, Lewa City. Iowa 52242
}

\begin{abstract}
Significant fluctuations in heart rate (HR) and arterial pressure occur during fetal life. However, the mechanisms regulating this normal variability are not completely understood. To test the hypothesis that the normal variability in fetal HR and blood pressure are produced by intrinsic fluctuations in sympathetic outflow, we recorded HR, mean arterial blood pressure (MABP), and renal sympathetic nerve activity (RSNA) in conscious, chronically instrumented, near-term fetal sheep $(n=5 ; 132-137$ $d$ of gestation, term being $145 \mathrm{~d}$ ) and correlated the relationships between RSNA and MABP, and RSNA and HR. RSNA, HR, and MABP were sampled at a frequency of 4 $\mathrm{Hz}$ and the values averaged by 5 -min blocks over a 4-h period. Linear regression analysis demonstrated a positive correlation between RSNA and both HR and MABP in all five fetuses $(p<0.02)$. In a second group of fetuses $(n=$ $5)$, ganglionic blockade with trimethaphan $(150-250 \mathrm{mg} /$ $\mathrm{kg} / \mathrm{min})$ significantly attenuated $(p<0.05)$ the coefficients of variation of HR $(12.3 \pm 1.9 \%$ versus $1.7 \pm 0.6 \%)$ and MABP $(5.8 \pm 0.6 \%$ versus $3.6 \pm 0.5 \%)$. These results demonstrate that, in the fetus, fluctuations in HR and MABP are mediated by changes in sympathetic outflow and suggest an important role for the autonomic nervous system in fetal cardiovascular regulation. (Pediatr Res 35: 250-254, 1994)
\end{abstract}

\section{Abbreviations}

HR, heart rate

MABP, mean arterial blood pressure

RSNA, renal sympathetic nerve activity

REM, rapid eye movement

It is well established that significant fluctuations in $\operatorname{HR}(1,2)$ and blood pressure (3) occur during fetal life. HR variability is used as an index of fetal well-being (4), although the mechanisms regulating cardiovascular function in the fetus are not well understood. Several investigators have demonstrated in healthy fetuses that baseline $\operatorname{HR}(1,3)$ and arterial pressure $(3,5)$ are related to changes in fetal behavioral patterns as measured by electrocortical activity. Zhu and Szeto (6) have further suggested that in fetal

Received July 19.1993: accepted September 29, 1993

Correspondence: Jeffrey L. Segar, M.D.. Assistant Professor, Department of Pediatrics, University of lowa Hospitals and Clinics, 200 Hawkins Dr.. Iowa City. IA 52242 .

Supported in part by the National Institutes of Health Grants HL-14388. DK38302 and DK-43961. J.L.S. is supported by Clinical Investigator Development Award HL-02865.

Presented in part at the Society for Pediatric Research meetings. Washington. DC, May 1993. sheep the variability in HR is related to fluctuations in sympathetic tone associated with changes in electrocortical activity. However, a direct relationship between the level of sympathetic activity and changes in HR or blood pressure has not previously been demonstrated. The present study used direct recording of efferent sympathetic nerve activity to test the hypothesis that the autonomic nervous system, in particular basal sympathetic activity, modulates resting arterial pressure and HR in the fetus.

\section{MATERIALS AND METHODS}

Surgical preparation. Studies were conducted in chronically instrumented fetal sheep $(n=10)$ between 132 and $137 \mathrm{~d}$ of gestation (term $=145 \mathrm{~d})$. Anesthesia and surgery of the ewe and fetus were performed as previously described $(7,8)$. Briefly, polyethylene catheters were placed into femoral arteries and veins: a catheter for recording amniotic pressure was secured to the fetal skin. The left kidney, renal artery, and renal nerves were exposed through a flank incision. After isolating a branch of the nerve bundle, platinum electrodes were secured onto the nerve for recording of RSNA as previously described (9). When function of the renal nerve was demonstrated by audible monitoring of pulse-synchronous bursts and examining oscilloscope tracings, the electrodes were secured with silicone gel (Sil-Gel 604A and 604B. Wacker-Chemie, Munich. Germany). A plastic-coated copper wire, used as a ground wire, was secured to the paravertebral muscle and the flank incision closed. Maternal incisions were closed in separate layers. All catheters were exteriorized through an s.c. tunnel and placed in a cloth pouch on the ewe's flank. Before surgery, $2 \mathrm{~g}$ of ampicillin was administered to the ewe, and $2 \mathrm{~g}$ were given intraamniotically at the end of surgery. All procedures were performed within the regulation of the Animal Welfare Act and the NIH Giuide for the Care and Use of Lahoratory Animals. At least $24 \mathrm{~h}$ were allowed for recovery from surgery before experiments were performed.

Experimental protocol. For the physiologic studies, the ewe was transferred to the laboratory in a small cart that was placed inside a Faraday cage. The ewe was then sedated with diazepam $(10 \mathrm{mg})$, given an i.v. bolus infusion of vecuronium bromide $(4.0$ $\mathrm{mg}$ ), intubated, and ventilated to maintain arterial blood values similar to those obtained during spontaneous respiration. Vecuronium was also administered to the fetus $(0.1 \mathrm{mg} / \mathrm{kg})$. Muscle paralysis was necessary to eliminate muscle movements that interfere with nerve recording. Diazepam $(2 \mathrm{mg})$ was given every $2 \mathrm{~h}$ to the ewe and additional doses of vecuronium were administered to the ewe and fetus when movement was detected. Sedation with diazepam and paralysis has previously been shown to have no effect on HR, arterial pressure, or plasma catecholamine concentrations in lambs (10). Throughout the experiment, a constant infusion of a solution containing $5 \%$ dextrose and $0.2 \%$ sodium chloride at a rate of $125 \mathrm{~mL} / \mathrm{h}$ was administered 
to the ewes. After intubation, a 1-h stabilization period was allowed before the start of the experiment.

During each experiment, MABP and amniotic pressure in fetuses were recorded continuously using Statham P23Db pressure transducers (Statham Instruments Division. Gould Inc., Valley View, $\mathrm{OH}$ ) and a Beckman R-611 Dynograph recorder (Beckman Instruments, Fullerton, CA). Fetal MABP was corrected relative to concomitant amniotic pressure. HR was monitored with a cardiotachometer triggered from the arterial pressure waves.

The renal nerve electrodes and ground wire were attached to a high-impedance probe (HIP5, Grass Instruments, Quincy, MA). The neural signal was amplified $(\times 20000)$ and filtered with a low-frequency cutoff at $100 \mathrm{~Hz}$ and a high-frequency cutoff at $1 \mathrm{kHz}$ using a Grass Bandpass Amplifier (P511). The amplified and filtered signal was visually displayed on an oscilloscope (511A. Tektronix, Beaverton, OR), routed to a Grass AM8 audio monitor. The amplified neural signal was rectified to make all voltages positive and integrated at rates of $0.5-1.0$ $\mathrm{Hz}$ using a 9873B Beckman voltage integrator. The rate of integration depended upon the quality of the neural signal and remained constant during all parts of the experiment for each animal. The integrated voltage and neurogram signals were displayed on a Beckman R611 Dynograph recorder and simultaneously recorded on-line to an IBM-XT computer using LABTECH NOTEBOOK (version 4.2. Laboratory Technologies. Wilmington, MA).

In the first group of fetuses $(n=5)$, basal HR, MABP. RSNA. and integrated RSNA were continuously recorded over a 4 -h period. In a second group of fetuses $(n=5)$, we examined the role of the autonomic nervous system on fetal cardiovascular homeostasis. After a 90 - to 120 -min control period similar to that described above, complete inhibition of sympathetic nerve activity was attained by a constant i.v. infusion of the ganglionic blocking agent trimethaphan $(150-250 \mathrm{mg} / \mathrm{kg} / \mathrm{min})$. After allowing for a $30-\mathrm{min}$ equilibration period, continuous recordings of $\mathrm{HR}$ and MABP were obtained. In both groups of fetuses, fetal and maternal arterial blood samples were obtained hourly for determination of arterial blood gases (BGM $1302 \mathrm{pH} / \mathrm{blood}$ gas analyzer). Noise within the neural signal was measured during ganglionic blockade and subtracted from the recorded signal before any calculation of change in RSNA.

Fetal HR, MABP, and RSNA values were sampled at a rate of $4 \mathrm{~Hz}$ and were averaged over 5 -min periods. For each animal in the first group, the relationships between RSNA and MABP or $\mathrm{HR}$ were determined by linear regression analysis using the least squared method. Group analysis was not performed because of differences in the rate of integration of the neural signal among animals. The coefficient of variation $(\mathrm{SD} /$ mean. expressed as a percentage) for each parameter measured was used as an index of variability. This method of analysis takes into account between-animals differences in HR and MABP (11). Statistical comparisons of arterial blood and hemodynamic values during $4 \mathrm{~h}$ of continuous recording were performed by analysis of variance and Newman-Keuls multiple comparisons procedure. The paired $t$ test was used to compare differences in HR and MABP variabilities during the control and ganglionic blockade periods as well as arterial blood gas values. Statistical significance was accepted when the $p$ value was less than 0.05 .

\section{RESULTS}

During the 4-h continuous recording. there was a small but significant decrease in arterial $\mathrm{pH}$ between the first $(7.33 \pm 0.02)$ and fourth $(7.26 \pm 0.04)$ hour of recording, although the values for arterial $\mathrm{PO}_{2}$ and $\mathrm{PCO}_{2}$ were similar between the two time periods (Table 1). No differences in resting HR (164 \pm 14 versus $153 \pm 13 \mathrm{bpm})$. MABP $(51 \pm 3$ versus $50 \pm 2 \mathrm{~mm} \mathrm{Hg})$, and RSNA $(1.51 \pm 0.1$ versus $1.54 \pm 0.7 \mathrm{U})$ were found between the first and fourth hour of recording, respectively. These $1-h$ average
Table 1. Resting arterial hlood and hemodinamic values during a 4 -h continuous recording in fetal she'p $(n=5)^{*}$

$\mathrm{pH}$

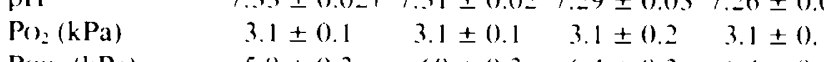
Hour 1 Hour 2 Hour 3 Hour 4

$\begin{array}{lllll}\mathrm{P}(\mathrm{O})_{2}(\mathrm{kPa}) & 5.9 \pm 0.3 & 60 \pm 0.3 & 6.4 \pm 0.3 & 0.4 \pm 0.4\end{array}$

$\begin{array}{lllll}H R(b p m) & 164 \pm 14 & 154 \pm 10 & 160 \pm 11 & 153 \pm 13\end{array}$

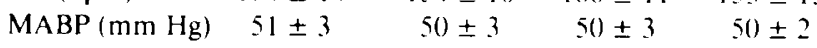

RSNA (U) $\quad 1.51 \pm 0.10 \quad 1.52 \pm 0.20 \quad 1.54 \pm 0.20 \quad 1.54 \pm 0.30$

* Values are means \pm SEM

$+p<0.05$ compared with $\mathrm{h} 4$.

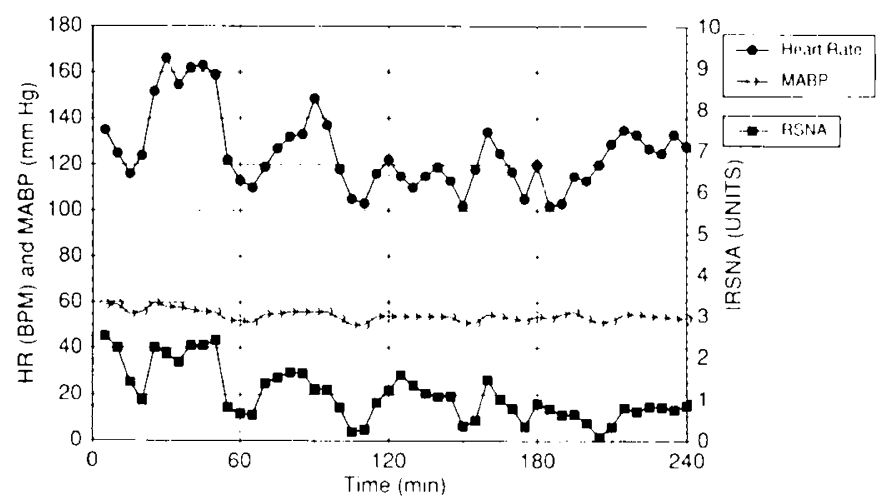

Fig. 1. Plot of 5-min averages of HR, MABP, and RSNA to show the range and association of the variability of these parameters in a fetal sheep.

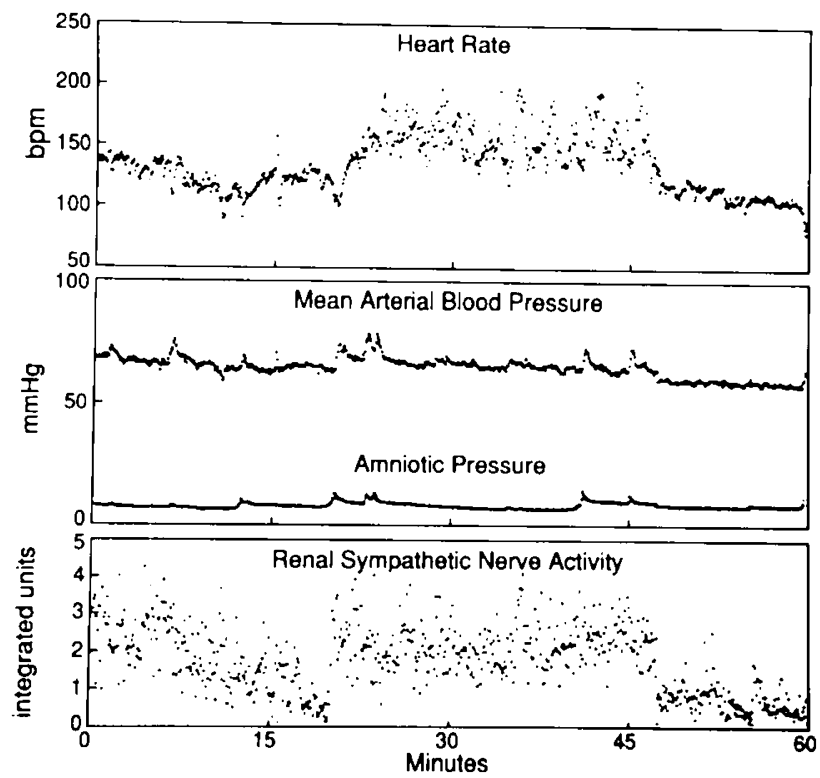

Fig. 2. Computer plot of fetal HR. MABP, amniotic pressure, and RSNA at 5-s intervals over a 1-h period. This hour coincides with the first hour in Figure 1.

values were similar to the average values for $\mathrm{HR}(159 \pm 9 \mathrm{bpm})$, $\operatorname{MABP}(50 \pm 2 \mathrm{~mm} \mathrm{Hg})$, and $\operatorname{RSNA}(1.53 \pm 0.02 \mathrm{U})$ for the complete 4-h recording.

A representative plot of HR, MABP, and RSNA expressed as 5 -min averages is shown in Figure 1 . This figure illustrates the range and variability in HR, RSNA, and to a lesser extent MABP that occurs over a 4 -h time period. In addition, the naturally occurring fluctuations in the parameters appear relatively concurrent and in similar directions. This relationship is also evident when 5-s averages for HR, MABP, and RSNA are examined (Fig. 2). Of note, the data in Figure 2 coincide with the first hour displayed in Figure 1. 
Using linear regression analysis, fetal HR and MABP both demonstrated a strong positive correlation $(p<0.05)$ with RSNA in all five fetal animals studied (Table 2). Figure 3 is a typical regression analysis of the relationships between $\mathrm{HR}$ or MABP and RSNA in a single fetus. Similar regression lines attained statistical significance in all fetuses studied. The slopes of the regression lines remained relatively constant among the animals (Table 2).

To determine whether the sympathetic nervous system contributes to the generation of HR and MABP variability, recordings of $H R$ and MABP were made in a second group of fetuses before and during continuous infusion of the ganglionic blocking agent trimethaphan (Fig. 4). Infusion of trimethaphan resulted in a significant attenuation of the variabilities in $\mathrm{HR}$ and MABP (Table 3). Ganglionic blockade also produced a significant reduction in HR (168 \pm 7 versus $126 \pm 7 \mathrm{bpm})$ and MABP $(53 \pm$ 2 versus $42 \pm 3 \mathrm{~mm} \mathrm{Hg}$ ) compared with control values. Arterial $\mathrm{pH}$ was lower during infusion of trimethaphan $(7.31 \pm 0.12)$ compared with control $(7.35 \pm 0.12)$, although no changes in $\mathrm{PO}_{2}$ or $\mathrm{PCO}_{2}$ were seen (Table 3).

\section{DISCUSSION}

In the near-term fetus, short- and long-term fluctuations in HR and arterial blood pressure have been well demonstrated (3, $12,13)$, although the mechanisms regulating these variations are not completely understood. Our study demonstrates strong positive correlations between changes in RSNA and HR, and RSNA and MABP. Furthermore, the variabilities in HR and RSNA are greatly attenuated after ganglionic blockade. Taken together, these results suggest that fluctuations in sympathetic outflow generate the observed variability in fetal $\mathrm{HR}$ and arterial pressure.

In the present study, we sought to measure centrally generated tonic sympathetic discharge by recording efferent RSNA. It is generally accepted that neural activity is an important regulator of vasomotor tone and ultimately the maintenance of arterial pressure within its physiologic range (14). By using continuous recordings of sympathetic nerve activity, we were able to correlate the level of activity with MABP and HR. Although rapid fluctuations in RSNA, MABP, and HR occur, we examined the

Table 2. Linear regression analysis values from 4-h continuous recording

\begin{tabular}{cccccccc}
\hline & \multicolumn{3}{c}{ RSNA is HR } & & \multicolumn{2}{c}{ RSNA } & vs MABP \\
\cline { 2 - 4 } $\begin{array}{c}\text { Animal } \\
\text { no. }\end{array}$ & $\begin{array}{c}\text { Slope } \\
(\mathrm{bpm} / \mathrm{U})\end{array}$ & $\begin{array}{c}r \\
\text { value }\end{array}$ & $\begin{array}{c}p \\
\text { value }\end{array}$ & $\begin{array}{c}\text { Slope } \\
(\mathrm{mm} \mathrm{Hg} / \mathrm{U})\end{array}$ & $\begin{array}{c}r \\
\text { value }\end{array}$ & $\begin{array}{c}p \\
\text { value }\end{array}$ \\
\hline 1 & 18.96 & 0.73 & 0.0001 & 3.08 & 0.85 & 0.0001 \\
2 & 27.33 & 0.73 & 0.0001 & 3.98 & 0.92 & 0.0001 \\
3 & 13.26 & 0.45 & 0.015 & 3.07 & 0.42 & 0.022 \\
4 & 11.06 & 0.51 & 0.016 & & 3.34 & 0.77 & 0.0001 \\
5 & 16.45 & 0.54 & 0.005 & 3.70 & 0.70 & 0.0001 \\
\hline
\end{tabular}

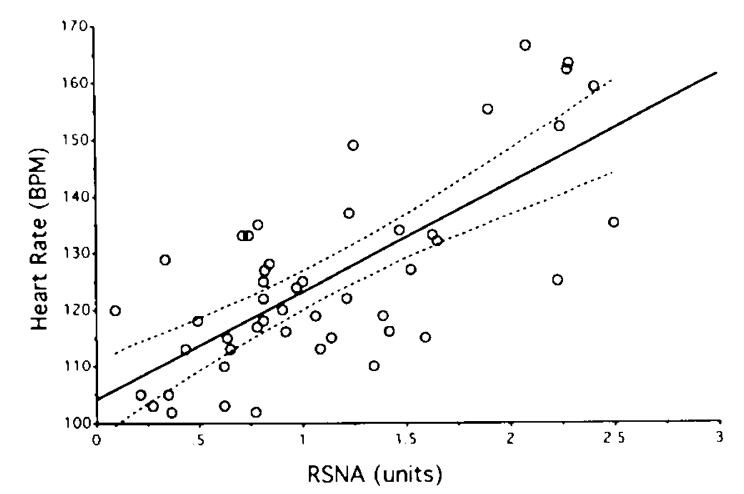

correlation over a long period of time $(4 \mathrm{~h})$ using 5 -min averages. This length of time was chosen to reduce the influence of baroreflex mechanisms on the average values of the measured parameters. The arterial baroreflex, which is functional and sensitive during fetal life (15), participates in the rapid adjustment of blood pressure around an existing pressure rather than in determination of the existing pressure itself (16). In contrast to our findings, studies in adult rats found a negative correlation between RSNA and MABP (17). However, these studies used a different method of analysis and examined a shorter period of time, and both differences likely allowed for baroreflex influence on the relationships examined.

The mechanisms involved in generating the large fluctuations in sympathetic activity during fetal life are not fully understood. Previous studies have suggested that the variations may be related to changes in behavior state $(1,6,13)$. In fetal sheep, which do not have an awake state but rather alternate between two behavioral states, REM and quiet (non-REM) sleep (18), HR and arterial pressure are highest during high-voltage low-frequency electrocortical activity (non-REM), and lowest during low-voltage high-frequency states (REM) $(1-3)$. Changes in other physiologic parameters including organ blood flow and cerebral oxygen consumption are also dependent upon electrocortical state $(3,5,19)$ and may be related to changes in autonomic activity. Because electrocortical activity was not recorded in the present study, we cannot determine whether changes in sympathetic outflow are related to behavioral state. Nonetheless, the fact that changes in behavioral state are associated with alterations in cardiovascular function, which in turn is determined by variations in sympathetic activity, suggests that electrocortical activity-related changes in autonomic activity may occur. One also cannot exclude that fetal breathing activity, which occurs primarily during REM sleep, may regulate sympathetic tone and cardiovascular function by activating pulmonary stretch receptors. Studies in adult animals examining the role of pulmonary stretch receptors in modulating cardiovascular function have shown that stimulation of these receptors decreases efferent sympathetic activity, resulting in peripheral vasodilation and a fall in arterial pressure $(12,20)$. However loading of these stretch receptors also inhibits vagal efferent discharge, thus inducing cardiac acceleration (21). Therefore, it appears unlikely that the fetal breathing activity during REM sleep has a strong influence on fetal HR.

The decrease in $\mathrm{pH}$ that developed over the course of the study could potentially activate chemoreceptors. However, given that activation of chemoreceptors results in reflex increases in sympathetic activity, and that no change in renal sympathetic outflow occurred during this time, a significant effect on chemoreceptors appears unlikely. The generation of the metabolic acidosis was surprising and may reflect the development of impaired uterine blood flow secondary to paralysis of the ewe. Metabolic acidosis did not develop in the ewe; however, maternal hyperoxia $\mathrm{PO}_{2}$

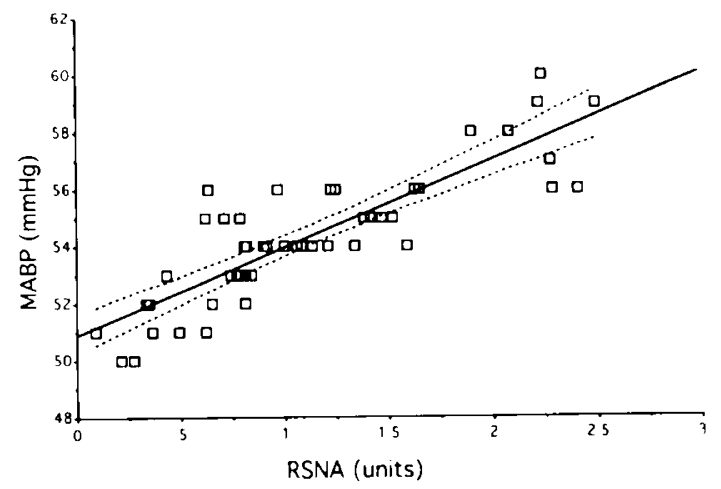

Fig. 3. Relationship between integrated RSNA and HR or MABP in a fetal sheep. Points are 5-min averages and represent those displayed in Figure 1. Dotted lines represent $95 \%$ confidence interval for line of best fit. 


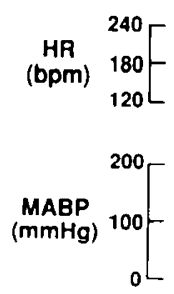

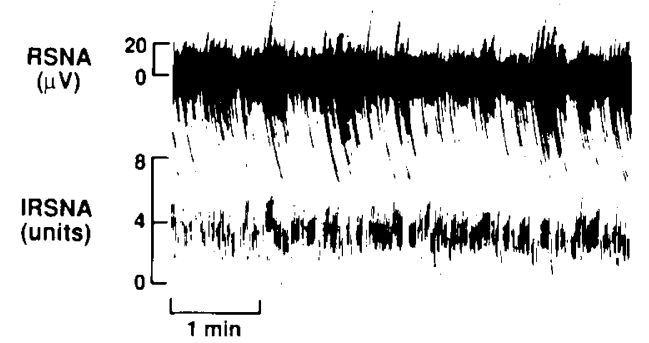

Fig. 4. Representative tracing of HR, MABP, neurogram for RSNA, and integrated RSNA (IRSN. 4$)$ before (comtro/) and during ganglionic blockade.

Table 3. Arterial blood and hemodynamic values before and after ganglionic blockade in fetal sheep $(n=5)^{*}$

\begin{tabular}{lcc}
\hline $\mathrm{pH}$ & Control & $\begin{array}{c}\text { Ganglionic } \\
\text { blockade }\end{array}$ \\
$\mathrm{PO}_{2}(\mathrm{kPa})$ & $7.35 \pm 0.12 \dagger$ & $7.31 \pm 0.12$ \\
$\mathrm{PCO}_{2}(\mathrm{kPa})$ & $2.6 \pm 0.3$ & $2.6 \pm 0.1$ \\
$\mathrm{HR}(\mathrm{bpm})$ & $5.3 \pm 0.3$ & $5.6 \pm 0.3$ \\
$\mathrm{MABP}(\mathrm{mm} \mathrm{Hg})$ & $168 \pm 7 \dagger$ & $126 \pm 7$ \\
$\mathrm{HR}$ variability $(\%)$ & $53 \pm 2 \dagger$ & $42 \pm 3$ \\
MABP variability $(\%)$ & $12.3 \pm 1.9 \dagger$ & $1.7 \pm 0.6$ \\
RSNA variability $(\%)$ & $58.2 \pm 0.6 \dagger$ & $3.6 \pm 0.5$ \\
\hline
\end{tabular}

* Variability $=\mathrm{SD} /$ mean. Values are means $\pm \mathrm{SEM}$

$+p<0.05$ compared with ganglionic blockade.

values of $150 \mathrm{~mm} \mathrm{Hg}(20 \mathrm{kPa})]$ may have helped prevent the development of fetal hypoxemia despite impaired uterine blood flow.

The significant decreases in HR and arterial pressure resulting from ganglionic blockade confirms the findings of previous studies in near-term fetal sheep (22). In preterm fetuses, ganglionic blockade has little effect on systemic hemodynamics, while during postnatal development, there is a gradual decline in the hypotensive effects of autonomic blockade $(22,23)$. These findings suggest that sympathetic tone is high late in fetal life and is important in the maintenance of fetal arterial pressure. In contrast, other investigators (24) have shown in near-term fetal sheep that chemical sympathectomy does not alter resting $\mathrm{HR}$ or MABP. However, chemical sympathectomy results in elevated levels of cortisol, vasopressin, and circulating catecholamines, as well as a supersensitivity to $\alpha$-adrenergic receptor agonists, all of which may be involved in the maintenance of HR and MABP $(25,26)$.

The present study demonstrates that fetal HR variability is mediated by neural mechanisms because ganglionic blockade attenuated this variability. Because $H R$ is influenced by both limbs of the autonomic nervous system, we cannot directly determine whether periods of cardiac acceleration are caused by increased sympathetic activity or withdrawal of parasympathetic tone to the heart. However, previous investigators (6) have demonstrated in the fetus that $\beta$-adrenergic blockade attenuates the cyclic variability in HR between low-voltage high-frequency and high-voltage slow activity states. In addition, the decrease in $\mathrm{HR}$ in response to $\beta$-blockade is greater during high-voltage low- frequency than during low-voltage high-frequency states. Furthermore, in adult animals, cardiac sympathectomy abolishes the decrease in HR during REM sleep (27). Taken together, these results suggest that during fetal life fluctuations in sympathetic outflow contribute to the variability in HR.

The degree of arterial pressure variability was similar to that previously reported in fetal lambs, rats, and unrestrained cats (28). The finding that ganglionic blockade attenuated arterial pressure variability in fetal sheep is surprising given that, in the absence of efferent sympathetic nerve activity to the vascular bed, baroreflex mechanisms, which act to buffer changes in arterial pressure, are made inoperable. Arterial baroreceptor denervation in fetal sheep is known to increase arterial pressure variability (28). Furthermore, in mature animals, both limbs of arterial baroreflex are essential in maintaining cardiovascular homeostasis because interruption of either the afferent limb (by sinoaortic denervation) or efferent limb (by ganglionic blockade) results in increased arterial pressure lability (29). Reasons for these differences may be related to differences in study design. species, degree of maturation, or peripheral hormonal influences (29). Nonetheless, it appears that changes in basal sympathetic tone play a more significant role in the generation of natural variations in blood pressure during fetal compared with postnatal life.

Although RSNA has been used by other investigators as a measure of central sympathetic outflow (17), it must be noted that RSNA may not always reflect changes in activity in other sympathetic nerves (30). Previous studies in mature animals have demonstrated that changes in sympathetic flow to skeletal muscles in response to select stimuli may be opposite of those observed in sympathetic fibers innervating the kidney and gastrointestinal tract (31). Similarly, sympathetic outflow to different organs also differs during hypotensive hemorrhage in adult rabbits, increasing in adrenal nerves and decreasing in renal nerves (32). Additional studies are necessary to determine whether similar relationships between sympathetic activity and HR or MABP exist for other sympathetic nerves during fetal life.

In summary, positive correlations exist between the level of sympathetic tone and resting MABP and HR during fetal life. Blockade of sympathetic activity markedly attenuates the naturally occurring variability in MABP and $\mathrm{HR}$. These results demonstrate that in the fetus, oscillations in MABP and HR are mediated by changes in sympathetic outflow and suggest an important role for the autonomic nervous system in fetal cardiovascular regulation. 


\section{REFERENCES}

1. Mann LI, Duchin S, Weiss RR 1974 Fetal EEG sleep stages and physiologic variability. Am J Obstet Gynecol 119:533-538

2. Wakatsuki A, Murata Y, Ninomoya Y. Masaoka N. Tyner JG, Kutty KK 1992 Physiologic baroreceptor activity in the fetal lamb. Am J Obstet Gynecol 167:820-827

3. Clapp JF. Szeto HH, Abrams R, Mann LI 1980 Physiologic variability and fetal electrocortical activity. Am J Obstet Gynecol 136:1045-1050

4. Boehm FH 1977 FHR variability: key to fetal well-being. Contemp Ob/Gyn 9:57-65

5. Jensen A. Bamford OS, Dawes GS. Hofmeyr G, Parkes MJ 1986 Changes in organ blood flow between high and low voltage electrocortical activity in fetal sheep. J Dev Physiol 8:187-194

6. Zhu Y. Szeto HH 1987 Cyclic variation in fetal heart rate and sympathetic activity. Am J Obstet Gynecol 156:1001-1(0)5

7. Robillard JE, Weitzman RE 1980 Developmental aspects of the fetal renal response to exogenous arginine vasopressin. Am J Physiol 238:F407-F4l4

8. Robillard JE, Nakamura KT. DiBona GF 1986 Effects of renal denervation on renal responses to hypoxemia in fetal lambs. Am J Physiol 250:F294F301

9. Smith FG, Klinefus JM, Koop UC. Robillard JE 1990) Novel recordings of renal sympathetic nerve activity in conscious fetal sheep and newborn lambs. Am J Obstet Gynecol 258:218-221

10. Smith F, Klunkefus J, Robillard J 1992 Effects of volume expansion on renal sympathetic nerve activity and cardiovascular and renal function in lambs. Am J Physiol 262:F2651-F2658

11. Zar JH 1984 Biostatistical Analysis. Prentice Hall. Englewood Cliffs, NJ

12. Bainton C, Richter D. Seller H. Ballantyne D. Klein J 1985 Respiratory modulation of sympathetic activity. J Auto Nerv Sys 12:77-90

13. Davidson SR, Rankin JHG, Martin CB, Reid DL 1992 Fetal heart rate variability and behavioral state: analysis by power spectrum. Am J Obstet Gynecol 167:717-7!2

14. Calaresu FR, Yardley CP 1988 Medullary basal sympathetic tone. Ann Rev Physiol 50:511-524

15. Segar JL. Hajduczok G. Smith BA. Robillard JE 1992 Ontogeny of baroreflex control of renal sympathetic nerve activity and heart rate. Am J Physiol 263:H1819-H1826

16. Kirscheim HR 1976 Systemic anterial baroreceptor reflexes. Physiol Rev 56:100-177

17. Barres C. Lewis SJ, Jacob HJ. Brody MJ 1992 Arterial pressure lability and renal sympathetic nerve activity are disassociated in SAD rats. Am J Physiol 263:R639-R646

18. Rigatto $\mathrm{H} 1992$ Control of breathing in fetal life and onset and control of breathing in the neonate. In: Polin RA. Fox WW (eds) Fetal and Neonatal Physiology. WB Saunders. Philadelphia, pp 790-801

19. Richardson BS. Patrick JE, Abduljabbar H 1985 Cerebral oxidative metabolism in the fetal lamb: relationship to electrocontical state. Am J Obstet Gynecol 153:426-431

20. Abboud F. Thames M 198.3 Interaction of cardiovascular reflexes in circulatory control. In: Shepard JT. Abboud FM (eds) Handbook of Physiology: The Cardiovascular System. American Physiological Society. Bethesda. MD, pp $675-753$

21. Angell-James JE. Daly MDeB 1978 The effects of artificial lung inflation on reflexly induced bradycardia associated with apnoea in the dog. J Physiol (Lond) 274:349-366

22. Nuwayhid B. Brinkman CR, Bevan JA, Assali NS 1975 Development of autonomic control of fetal circulation. Am J Physiol 228:237-344

23. Woods JR Dandavino A Murayama K. Brinkman CR. Assali NS 1977 Autonomic control of cardiovascular functions during neonatal development and in adult sheep. Circ Res 40:401-407

24. Tabash K, Numayhid B. Assali NS 1982 Circulatory effects of chemical sympathectomy in fetal, neonatal and adult sheep. Am J Physiol 243:H113 H 122

25. Iwamota HS, Rudolph AM, Mirkin BL. Keil LC 1983 Circulatory and humoral responses of sympathectomized fetal sheep to hypoxemia. Am J Physiol 245: $\mathrm{H} 267-\mathrm{H} 772$

26. Jones CT. Roebuck MM. Walker DW. Langercrantz. HC. Johnston BM 1987 Cardiovascular. metabolic and endocrine effects of chemical sympathectomy and of adrenal demedullation in fetal sheep. J Dev Physiol 9:347-367

27. Baust W, Bohner B 1969 The regulation of heart rate during sleep. Exp Brain Res 7:169-180

28. Yardly RW. Bowes G. Wilkinson M. Cannata JP. Maloney JE. Ritchie BC. Walker AM 1983 Increased arterial pressure variability after arterial baroreceptor denervation in fetal lambs. Circ Res 52:580-588

29. Alper RH, Jacob HJ. Brody MJ 1987 Regulation of arterial pressure lability in rats with chronic sinoaortic deafferentation. Am J Physiol 253:H466-H474

30. Beluli DJ, Weaver LC 1991 Differential control of renal and splenic nerves without medullary topography. Am J Physiol 260: $\mathrm{H} 1072-\mathrm{H} 1079$

31. Futero-Neto HA. Coote JH 1982 Changes in synaptic activity to heart and blood vessels during desynchronized sleep. Brain Res 252:259-268

32. Victor RG. Thoren PN, Morgan DA. Mark AL 1989 Differential control of adrenal and renal sympathetic nerve activity during hemorrhagic hypotension in rats. Circ Res 64:686-694 